\title{
THE
}

\section{Impact of Hemlock Woolly Adelgid (Hemiptera: Adelgidae) Infestation on the Jasmonic Acid-Elicited Defenses of Tsuga canadensis (Pinales: Pinaceae)}

Chad M. Rigsby

Ian G. Kinahan

Amelia May

Amy Kostka

Nick Houseman

Follow this and additional works at: https://digitalcommons.uri.edu/bio_facpubs

The University of Rhode Island Faculty have made this article openly available. Please let us know how Open Access to this research benefits you.

This is a pre-publication author manuscript of the final, published article.

Terms of Use

This article is made available under the terms and conditions applicable towards Open Access Policy Articles, as set forth in our Terms of Use.

\section{Citation/Publisher Attribution}

Chad M Rigsby, Ian G Kinahan, Amelia May, Amy Kostka, Nick Houseman, Suzanne K Savage, Elizabeth R Whitney, Evan L Preisser, Impact of Hemlock Woolly Adelgid (Hemiptera: Adelgidae) Infestation on the Jasmonic Acid-Elicited Defenses of Tsuga canadensis (Pinales: Pinaceae), Environmental Entomology, nvaa104, https://doi-org.uri.idm.oclc.org/10.1093/ee/nvaa104 


\section{Authors}

Chad M. Rigsby, Ian G. Kinahan, Amelia May, Amy Kostka, Nick Houseman, Suzanne K. Savage, Elizabeth R. Whitney, and Evan L. Preisser 
1 Impact of hemlock woolly adelgid (Adelges tsugae) (Hemiptera: Adelgidae) infestation on

2 the jasmonic acid-elicited defenses of eastern hemlock (Tsuga canadensis)

3

4 Chad M. Rigsby ${ }^{1,2,3}$, Ian G. Kinahan ${ }^{1}$, Amelia May ${ }^{1}$, Amy Kostka ${ }^{1}$, Nick Houseman ${ }^{1}$,

$5 \quad$ Suzanne K. Savage ${ }^{1}$, Elizabeth R. Whitney ${ }^{1}$, and Evan L. Preisser ${ }^{1}$

6

$7 \quad{ }^{1}$ Department of Biological Sciences, The University of Rhode Island, Kingston, RI, USA

$8 \quad{ }^{2}$ Author for correspondence: crigsby @bartlettlab.com

$9 \quad{ }^{3}$ Current Address: Bartlett Tree Research Laboratories, The Morton Arboretum, Lisle, IL, USA

10

11

12

13

14

15

16

17

18 


\section{Abstract}

Hemlock woolly adelgid ('HWA') is an invasive piercing-sucking insect in eastern North America, which upon infestation of its main host, eastern hemlock ('hemlock'), improves attraction and performance of folivorous insects on hemlock. This increased performance may be mediated by HWA feeding causing antagonism between the the jasmonic acid and other hormone pathways. In a common garden experiments using HWA infestation and induction with methyl jasmonate (MeJA) and measures of secondary metabolite contents and defense-associated enzyme activities, we explored the impact of HWA feeding on the local and systemic induction of JA-elicited defenses. We found that in local tissue HWA or MeJA exposure resulted in unique induced phenotypes, while the combined treatment resulted in an induced phenotype that was a mixture of the two individual treatments. We also found that if the plant was infested with HWA, the systemic response of the plant was dominated by HWA, regardless of whether MeJA was applied or not. Interestingly, in the absence of HWA, hemlock plants had a very weak systemic response to MeJA. We conclude that HWA infestation prevents systemic induction of JA-elicited defenses. Taken together, compromised local JA-elicited defenses combined with weak systemic induction could be major contributors to increased folivore performance on HWA-infested hemlock.

Key Words: induced defenses, systemic induction, invasive forest pest, herbivory, conifers

\section{Introduction}


Plants growing under the resource-limited conditions typical of natural systems must

42 choose how to allocate scarce resources to functions such as growth, reproduction, and defense.

43 The induction of chemical and physical defenses in response to herbivore or pathogen attack is

44 hypothesized to be an energetically advantageous solution to such dilemmas (Baldwin 1998;

45 Gómez et al. 2007). When attacked by mobile herbivores that can respond to local defense by

46 seeking out undefended plant biomass, plants can respond via systemic responses that stimulate

47 defense induction in both damaged and undamaged tissues (Kant et al. 2015). Because they incur

48 energetic costs in tissue that has not yet been - and might not be - attacked, systemic defenses

49 are often considered a bet-hedging strategy: the cost of systemic induction is roughly half the

50 cost borne by non-systemically-induced plants that are attacked (Reynolds et al. 2019).

Systemic induction can be influenced by vascular architecture and connectivity, plant size

52 and age, and volatile production (Orians 2005; Kant et al. 2015). Several endogenous compounds

53 that act as systemic signals include phytohormones, peptides, and volatile compounds (Kant et

54 al. 2015). Jasmonates appear particularly important for systemic defense induction (Heil and Ton

55 2008). Precursors to jasmonic acid (JA) conjugates, such as JA itself, are produced at the site of

56 herbivore attack and transported through the phloem to undamaged tissues (Fürstenberg-Hägg et

57 al. 2013). JA-elicited systemic defense expression requires both JA biosynthesis at the site of

58 damage and JA perception in distant undamaged tissues (Heil and Walters 2009). A substantial

59 set of literature has demonstrated the antagonistic relationship between salicylic acid (SA) and

60 JA where the SA-induced monomerization of NONEXPRESSOR OF PATHOGENESIS-

61 RELATED GENES1 (NPR1) suppresses JA biosynthesis and inhibits JA-responsive genes

62 (Beckers and Spoel 2006). This antagonistic relationship suggests that the expression of JA- 
63 elicited systemic defense in distal plant tissues would be compromised if locally-produced SA

64 interfered with JA biosynthesis at the attack site.

Hemlock woolly adelgid (HWA; Adelges tsugae Annand) is a sessile, stylet-feeding insect that is invasive to eastern North America. It has caused mass mortality of eastern hemlock

67 ('hemlock'; T. canadensis L.) (Pinales: Pinaceae) within its invaded range. Chronic HWA

68 infestation causes a 'hypersensitive-like' response in hemlock that is characterized by the accumulation of SA, hydrogen peroxide $\left(\mathrm{H}_{2} \mathrm{O}_{2}\right)$, and proline and increases in methyl salicylate

70 (MeSA) emissions (Radville et al. 2011; Gómez et al. 2012; Pezet et al. 2013; Pezet and Elkinton

712014 Schaeffer et al. 2018; Rigsby et al. 2019). The nature of this response led to the hypothesis

72 that HWA infestation would increase host quality for JA-eliciting herbivores by decreasing the

73 induction of JA-linked plant defenses. Consistent with this scenario, Wilson et al. (2016)

74 reported increased performance of hemlock looper (Lambdina fiscellaria) on HWA-infested

75 hemlock, and Kinahan et al. (2020) found increased gypsy moth (Lymantria dispar) larval

76 preference for and performance on HWA-infested hemlocks in both field and laboratory settings.

77 Although the latter two studies are consistent with the hypothesis that HWA-mediated

78 increases in SA disrupt JA-based plant defense, this linkage has not been experimentally

79 confirmed. While changes in the inducibility of JA-elicited defenses may be involved, SA- and

80 JA-elicited defense responses are remarkably similar in hemlock (Rigsby et al. 2019). In an

81 experiment that used HWA and gypsy moth larvae to directly induce SA- and JA-elicited

82 responses, Rigsby et al. (in review) found that both HWA and gypsy moth increased foliar SA

83 levels; simultaneous herbivory by both insects had an additive effect. Gypsy moth herbivory

84 resulted in accumulation of JA and JA-Ile, the active form of JA, while HWA inhibited the

85 ability of gypsy moths to elicit JA accumulation (Rigsby et al. in review). These findings support 
86 the hypothesis that HWA infestation prevents hemlock from accumulating JA phytohormones in

87 response to JA-eliciting herbivores. Intriguingly, however, HWA infestation also increased

88 accumulation of several bioactive gibberellins (GAs), hormones known to play a critical role in

89 plant growth (i.e., stem elongation and leaf expansion; Davière and Achard 2013). This HWA-

90 elicited GA accumulation is notable because GAs are also known to antagonize JA signaling (de

91 Lucas et al. 2008). This result suggests that JA accumulation and the elicitation of JA-linked

92 defenses could be compromised by one or both of these mechanisms.

93 Previous research addressing herbivore-herbivore interactions in the HWA/hemlock

94 system has focused on local plant defense induction (i.e., changes occurring at the site of plant

95 damage); the impacts of HWA on systemic defense induction have not been addressed. We

96 present the results of work assessing the potential for HWA-induced suppression of JA-elicited

97 systemic defense induction. Using a common garden planting that contained both HWA-infested

98 and HWA-free hemlock saplings, we induced stems with methyl jasmonate (MeJA), a

99 methylated form of JA whose topical application induces JA-elicited responses in hemlock

100 (Rigsby et al. 2019). We evaluated induction responses by quantifying chemical and

101 physiological defensive responses (e.g., total soluble phenolics, peroxidase activity, etc) in

102 foliage on stems directly sprayed with MeJA and needles not directly sprayed, but on the same

103 branch. We hypothesized that (1) HWA infestation would attenuate local MeJA-elicited defense

104 responses, in accordance with Rigsby et al. (2019), but would completely shut down MeJA-

105 elicited systemic responses. Conversely, we predicted that (2) both local and systemic responses

106 would be uninhibited in HWA-free plants.

107 Materials and Methods 
Hemlock common garden, treatments, and sampling. In early spring 2014, 350 herbivorefree hemlock saplings (0.5-0.7 $\mathrm{m}$ tall) that were grown from seed collected in Pennsylvania and had not been treated with insecticides were purchased from Vans Pines Nursery (West Olive, MI). The 320 healthiest of these trees were planted in five 64-tree blocks (eight rows and columns with trees spaced 1-1.5 m apart) into the understory of a mixed hardwood stand at the Kingston Wildlife Research Station (South Kingstown, RI) in April 2014. As part of ongoing experiments in our laboratory, a subset of trees within each block were randomly selected for artificial infestation with HWA, performed every year at approximately mid-spring (timed with crawler emergence). Briefly, we cut HWA-infested stems from naturally growing hemlocks located less than one $\mathrm{km}$ from our experimental site, inspected this foliage for the presence of only HWA, and secured this cut foliage to each hemlock within this treatment using wire to secure this cut foliage to each hemlock (see Butin et al. 2007 for detailed methods). Trees in the control treatment were sham-inoculated with herbivore-free foliage to control for inoculationrelated disturbance. The uninfested status of each control tree was confirmed via careful visual inspection of each tree prior to the removal of any foliage. Trees were protected from herbivory and treatment cross-contamination with chicken-wire cages covered in mesh bags (Agribon-15, Johnny’s Selected Seeds, Waterville, ME, USA; 90\% light transmission).

Twelve trees from each of the two treatments (HWA-infested, uninfested controls) were selected so that each treatment was represented by at least three trees in each of four spatial blocks; trees from the fifth spatial block was excluded because this block was much shadier than the other four. A single branch was selected on each tree; all sampled branches were of similar length and diameter (ANOVA; $P>0.05$ for all) and the branches from HWA-infested trees had moderate, but roughly equivalent HWA densities (0.5-1 $\mathrm{HWA} \mathrm{cm}^{-1}$ stem). Each branch was 
131 marked by placing flagging placed at its base (Fig. 1). Twice weekly for a two-week period (28

132 Aug - 7 Sept 2017), an elicitor solution containing $10 \mathrm{mM}$ MeJA in a carrier solution of $0.1 \%$

133 (v:v) Tween 20 (MeJA treatment) or carrier solution only (control treatment) was carefully

134 applied using a fine-tipped paint brush, so that MeJA solution did not run off, to the first lateral

135 stem proximal to the terminal stem, near the flagging. All treated branches were harvested on 11

136 Sept, placed in aluminum foil, and stored at $-80^{\circ} \mathrm{C}$. In order to understand how HWA impacts

137 systemic defense signaling, we harvested a stem immediately proximal (denoted as "Systemic"

138 stem) to the treated stem (denoted as "Local" stem) (Fig. 1). This resulted in four treatment

139 combinations (HWA +/- and MeJA +/-; n = 6 biological replicates per treatment combination; 24

140 total), with two location categories per branch: "Local" and "Systemic" stems (48 total samples;

141 Fig. 1). Lastly, in order to eliminate additional sources of variation, only foliage produced in the

142 current growing season (i.e., newly produced foliage) was used in this study, foliage that was

143 produced prior to the season of our experiment was not used in this study (Fig. 1).

Chemical and Physiological Analyses. Crude levels of chemical defenses were quantified

145 as described in Rigsby et al. (2019); any deviations from these protocols are detailed below.

146 Briefly, needles were ground into a powder in liquid nitrogen using a mortar and pestle and 100

$147 \mathrm{mg}$ were placed in a $2 \mathrm{ml}$ microtube. Tissue was twice-extracted in $0.5 \mathrm{ml}$ HPLC-grade

148 methanol. Following centrifugation at $16,000 \mathrm{~g}\left(10 \mathrm{~min}, 4^{\circ} \mathrm{C}\right)$, the supernatants were combined.

149 Methanol-soluble terpene content was quantified immediately using chloroform and $\mathrm{H}_{2} \mathrm{SO}_{4}$

150 (Rigsby et al. 2019) with linalool as the standard. Soluble phenolic content was quantified via the

151 Folin-Ciocalteu method using chlorogenic acid as standard; proanthocyanidin content was

152 quantified using the acidified butanol method (Rigsby et al. 2019). Chlorogenic acid was used as

153 a standard for the quantification of soluble phenolics because prior research found that 
154 chlorogenic acid dominates the soluble phenolic profile of hemlock foliage (Rigsby et al. 2020).

155 The cell wall-bound phenolic (CW-bound phenolic) and lignin contents were determined as per

156 Rigsby et al. (2019) using gallic acid and spruce lignin, respectively, as the standard. Hydrogen

157 peroxide $\left(\mathrm{H}_{2} \mathrm{O}_{2}\right)$ was quantified according to the KI method (Junglee et al. 2014; Rigsby et al. 158 2019).

For enzyme activity assays, $200 \mathrm{mg}$ needle powder was extracted on ice in five volumes of extraction buffer $\left(50 \mathrm{mM} \mathrm{NaPO}_{4}, \mathrm{pH} 6.8,10 \%\right.$ PVPP, 5\% Amberlite XAD4 resin, and $1 \mathrm{mM}$ 161 EDTA) and the 10,000 $g$ supernatant was used as the source of enzymes. Chitinase (CHI) and 162 lipoxygenase (LOX) activities were quantified according to Rigsby et al. (2016) using chitin 163 azure $\left(\mathrm{OD}_{575} \mathrm{mg}^{-1}\right)$ and linoleic acid $\left(\mu\right.$ moles $\left.\min ^{-1} \mathrm{mg}^{-1}\right)$, respectively, as substrates. Peroxidase 164 (POX) activity was quantified according to Rigsby et al. (2018) using guaiacol and $\mathrm{H}_{2} \mathrm{O}_{2}$ as 165 substrates $\left(\mu\right.$ moles $\mathrm{min}^{-1} \mathrm{mg}^{-1}$ ). Phenylalanine ammonia lyase (PAL) activity was quantified by 166 monitoring the conversion of L-phenylalanine to trans-cinnamic acid (Chen et al. 2006; nmoles $\left.167 \mathrm{hr}^{-1} \mathrm{mg}^{-1}\right)$. To express enzyme activities per unit protein, the protein content of extracts was 168 determined using the Bradford (1976) method with bovine serum albumin as standard. During 169 preliminary experiments, we attempted to detect polyphenol oxidase activity using multiple 170 substrates, as well as trypsin inhibitor activity, but were unable to do so.

172 induction), and their interactions on relative metabolite levels and enzyme activities was assessed 173 using an ANOVA with stem position nested within tree identity. An ANCOVA was initially 174 used with block as a covariate; because block was never significant, we proceeded with 175 ANOVAs. We were interested in detecting (1) within-treatment differences in foliar position 176 (i.e., 'Local' vs. 'Systemic' within a single treatment combination) and (2) between-treatment 
177 differences for a given foliar position (i.e., 'HWA-/MeJA-' vs. 'HWA+/MeJA-' vs. 'HWA-

178 /MeJA+' vs. 'HWA+/MeJA+' within a single sampling position). For post-hoc comparisons of

179 within-treatment differences between sampling positions, we used $t$-tests to directly compare

180 Local and Systemic foliage. For post-hoc comparisons of treatment combinations within a

181 sampling position, we first performed $t$-tests comparing all combinations of interest, then the

182 resulting $P$-values were adjusted via the Benjamini-Hochberg procedure (Benjamini and

183 Hochberg 1995). For example, if comparing all four treatment combinations of 'Local' foliage,

184 the six calculated $P$-values were included in the Benjamini-Hochberg correction. Because

185 different sampling positions from different treatments were not of interest (e.g., 'Local' foliage

186 from 'HWA+/MeJA-' vs. 'Systemic' foliage from 'HWA-/MeJA-'), these comparisons were not

187 made. These post-hoc procedures was only used if significant interactions between

188 treatments/sampling locations were detected. All statistical analyses were performed in $\mathrm{R}(\mathrm{R}$

189 Development Core Team 2020).

190 Results

Secondary Metabolites. For both Local and Systemic foliage, CW-bound phenolics,

192 lignin, and $\mathrm{H}_{2} \mathrm{O}_{2}$ all had increased tissue levels as a result of HWA infestation relative to

193 uninfested controls (Figs. 2A, 2B, and 2C, respectively). The application of MeJA had no effect

194 on CW-bound phenolic or $\mathrm{H}_{2} \mathrm{O}_{2}$ contents in either Local or Systemic foliage (Figs. 2A and 2C,

195 respectively), but did cause lignin to accumulate in Local foliage in the absence of HWA.

196 However, this lignin accumulation was attenuated in the presence of HWA in Local foliage (Fig.

197 2B). Foliage position (i.e., "Local" vs. "Systemic" foliage) had a significant effect on lignin and

$198 \mathrm{H}_{2} \mathrm{O}_{2}$ contents. In the absence of HWA, MeJA application (HWA-/MeJA+) significantly

199 increased lignin content in Local foliage but not in adjacent Systemic foliage (Fig. 2B). 
Additionally, in the presence of HWA and when MeJA was applied (HWA+/MeJA+), $\mathrm{H}_{2} \mathrm{O}_{2}$ content was significantly greater in Systemic than in Local foliage (Fig. 2C). There were no elicitor treatment or sampling location effects for soluble phenolics $\left(71.70 \pm 1.05 \mathrm{mg} \mathrm{g}^{-1} \mathrm{DW}\right)$, proanthocyanidins $\left(33.54 \pm 1.32 \mathrm{OD}_{550} \mathrm{~g}^{-1} \mathrm{DW}\right)$, or methanol-soluble terpenes $(14.05 \pm 0.15 \mathrm{mg}$ $\left.\mathrm{g}^{-1} \mathrm{DW}\right)$.

Defensive Enzyme Activities. In both Local and Systemic foliage, HWA infestation increased POX activity (Fig. 3A), while the application of MeJA increased LOX and PAL activities in Local foliage, only (Figs. 3B and 3C, respectively). Interestingly, infestation by HWA had no effect on the MeJA-elicited increase in LOX activity in Local foliage (i.e., the increase in LOX activity caused by MeJA application was not attenuated by the presence of HWA in Local foliage). However, this was the case for PAL activity, as HWA infestation severely inhibited the MeJA-elicited increase in PAL activity in Local foliage (Fig. 3C). Foliage position (i.e., "Local" vs. "Systemic" foliage) had a significant effect on both LOX and PAL activities. As with lignin content, the increase in LOX and PAL activities that were found in Local foliage in the absence of HWA and with MeJA application (HWA-/MeJA+), did not occur in Systemic foliage (Figs. 3B and 3C). This was also the case for LOX activity in the presence of HWA and with MeJA application (HWA+/MeJA+), where MeJA application resulted in increased activity in Local but not in Systemic foliage (Fig. 3A). There were no elicitor treatment or sampling location effects for CHI activity $\left(0.31 \pm 0.01 \mathrm{OD}_{575} \mathrm{mg}^{-1}\right)$.

\section{Discussion}

The systemic induction of defenses is considered an important bet-hedging strategy for plants to minimize fitness costs (Reynolds et al. 2019), and systemic induction is viewed as an adaptive response against herbivores that impose chronic injury, continually increase populations 
223 on individual plants, and/or can move among plant parts (Mason et al. 2017). Like many woody

224 plants, an abundance of folivorous insects utilize hemlock as a host resource, including a variety

225 of leafminers, loopers, leafrollers, budworms, needleworms, tussock moths, cutworms, and

226 others (Maier et al. 2011). Recent research has shown that HWA infestation increases the

227 attraction to and performance of folivorous insects on hemlock (Wilson et al. 2016; Rigsby et al.

228 2019; Kinahan et al. 2020), and this increase in folivore performance may be facilitated by the

229 compromising of JA-elicited defenses locally at the site of folivore attack (Rigsby et al. 2019;

230 2020). This study sought to investigate the impact of HWA infestation on the induction of

231 systemic, JA-elicited defenses. We hypothesized that (1) the HWA-instigated attenuation of local

232 JA induction would be accompanied by a complete lack of systemic responses, and that (2)

233 systemic responses would occur on HWA-free plants.

With regards to our first hypothesis that HWA infestation would attenuate local MeJA-

235 elicited defense responses, our data somewhat agree with this though defenses presented rather

236 as a blend between HWA-induced and MeJA-induced responses. This was consistent with

237 previous research that found local JA-elicited defense expression is altered by HWA infestation

238 (Rigsby et al. 2019). The second part of the hypothesis, that this local attenuation would be

239 accompanied by complete inhibition of systemic responses, which also appears to be supported

240 generally as systemic defense expression was completely masked by the local response to HWA

241 infestation. Patterns of metabolite accumulation and enzyme activities of this treatment-position

242 combination (i.e., systemic HWA+/MeJA+) was most similar to both the local and systemic

$243 \mathrm{HWA}+/ \mathrm{MeJA}$ - treatments. Even if JA-elicited host responses were not locally compromised, the

244 lack of systemic responses to mobile herbivores would pose a serious problem for a woody plant,

245 as mobile folivores could simply move to these undefended tissues (Mason et al. 2017). 
The apparent lack of systemic induction by MeJA+ plants was unanticipated and the

247 opposite of our second hypothesis. Several variables could have contributed to this, such as

248 interspecific species variation in systemic inducibility (e.g., Heil and Ploss 2006), site conditions

249 (e.g., shade is known to inhibit JA responses; Cipollini 2004), MeJA dose (e.g., Naidoo et al.

250 2013), and/or vascular architecture (e.g., the stems chosen for our experiment may not have been

251 as connected as we perceived; Orians 2005). However, the differential responses of LOX and

252 PAL activities in the systemic tissues was particularly interesting (Figs. 3A and 3C). The activity

253 of LOX, which should be an excellent of JA-elicitation indicator as it is directly involved in JA

254 synthesis (Beckers and Spoel 2006) and directly (Felton et al. 1994) and indirectly (War et al.

255 2012) involved in defense, was not increased systemically by MeJA. However, PAL activity was

256 increased systemically with MeJA application, perhaps demonstrating that PAL activity may

257 better indicate JA-elicitation than LOX activity. Regardless of this, systemically increased PAL

258 activity indicates that some sort of signal likely made it to this stem and was perceived by these

259 tissues.

260 Interestingly, we did not detect local or systemic accumulation of soluble phenolics,

261 including proanthocyanidins, and methanol-soluble terpenes. These classes of secondary

262 metabolites are known to be critically important anti-herbivore defenses in conifers (Raffa et al.

263 2017). Previous research showed significant, positive effects of both HWA infestation and MeJA

264 application on soluble phenolic content, including proanthocyanidins (Rigsby et al. 2019).

265 Similar levels of CHI activity across all treatment combinations was also unanticipated, since

266 previous research found that the activity of this enzyme was strongly enhanced by HWA

267 infestation and MeJA application (Rigsby et al. 2019). In agreement with this previous research,

268 we detected accumulation of $\mathrm{CW}$-bound phenolics and $\mathrm{H}_{2} \mathrm{O}_{2}$, and increases in POX activity in 
269

270

271

272

273

274

275

276

277

278

279

280

281

282

283

284

285

286

287

288

289

290

291

response to HWA infestation, and a strong positive effect of MeJA application on LOX activity (Rigsby et al. 2019). One difference between these two experiments is that Rigsby et al. (2019) used potted hemlocks in full sun while this study used hemlocks planted in the understory of a mixed hardwood stand. It may be that some aspect(s) of these environmental differences had some effect on hemlock response to our treatments. In addition to normal growth, GAs are also associated with shade-avoidance and growth, and JA pathways interact directly and antagonistically through DELLA-JAZ interactions (Wasternack and Hause 2013; Davière and Achard 2016), and shaded plants are often unable to activate JA-elicited responses (Cipollini 2004). HWA has a positive effect on a few major GAs (Rigsby et al. In Review), and the addition of shade may further increase gibberellin accumulation and antagonization of the JA pathway. An additive or synergistic effect between HWA infestation and shade on the inducibility of JAelicited defenses would have major impacts on hemlock herbivore interactions, including between hemlock and HWA, itself. It has been noted by many researchers and practitioners that HWA appears to perform substantially better on its host when hemlock is shaded (Hickin and Preisser 2015).

The systemic induction of defenses is thought to be an important strategy of plants to reduce fitness costs (Kant et al. 2015; Reynolds et al. 2019), especially against herbivores that can move between plant tissues (Mason et al. 2017). Field observations and laboratory assays have shown dramatic increases in host quality and attraction to these kinds of herbivores (Wilson et al. 2016; Rigsby et al. 2019; Kinahan et al. 2020). In this study, we found that host responses to HWA infestation essentially overwhelm and prevent JA-elicited systemic defense expression, but we also detected very little JA-elicited systemic responses in hemlock in the absence of HWA. We conclude that in the absence of HWA, some JA-associated signal may be translocated 
292 and systemically perceived, as evidenced by significantly elevated PAL activity. Environmental 293 conditions of our experiment may have played a role in this lack of response, however, hemlock 294 often exists in the environment in dense, shaded conditions (Hadley 2000), still allowing our 295 results to be ecologically meaningful. Future research should explore the role of shade on local 296 and systemic SA- and JA-elicited responses in hemlock.

298 Acknowledgements The authors thank K. Andrews and A. Bach of The University of Rhode Island INBRE 300 facility. This research was funded by National Science Foundation grant NSF-DEB 1256769 to 301 E. Preisser, and C. Rigsby was supported by USDA McIntire-Stennis RI0017-MS979. 


\section{References}

Baldwin, I. T. 1998. Jasmonate-induced responses are costly but benefit plants under attack in native populations. Proc. Natl. Acad. Sci. USA. 95: 8113-8118.

Beckers, G. J. M., and S. H Spoel. 2006. Fine-tuning plant defence signaling: Salicylate versus jasmonate. Plant. Biol. 8: 1-10.

Benjamini, Y., and Y. Hochberg. 1995. Controlling the false discovery rate: a practical and powerful approach to multiple testing. J. R. Stat. Soc. B 57: 289-300.

Butin, E., E. L. Preisser, and J. S. Elkinton. 2007. Factors effecting settlement rate of the hemlock woolly adelgid, Adelges tsugae. Agric. For. Entomol. 9: 215-219.

Chen, J-Y., P-F. Wen, W-F. Kong, Q-H. Pan, J-C. Zhan, J-M. Li, and W-D. Huang. 2006. Effect of salicylic acid on phenylpropanoids and phenylalanine ammonia-lyase in harvested grape berries. Postharvest Biol. Tec. 40: 64-72.

Cipollini, D. 2004. Stretching the limits of plasticity: Can a plant defend against both competitors and herbivores?. Ecology. 85: 28-37.

Davière, J-M., and P. Achard. 2013. Gibberellin signaling in plants. Development. 140: 11471151.

Davière, J-M., and P. Achard. 2016. A pivotal role of DELLAs in regulating multiple hormone signals. Mol. Plant. 9: 10-20.

de Lucas, M., J-M. Davière, M. Rodríguez-Falcón, M. Pontin, J. M. Iglesias-Pedraz, S. Lorrain, C. Fankhauser, M. A. Blázquez, E. Titarenko, and S. Prat. 2008. A 
molecular framework for light and gibberellin control of cell elongation. Nature. 451: 480-483.

Felton, G. W., C. B. Summers, and A. J. Mueller. 1994. Oxidative responses in soybean foliage to herbivory by bean leaf beetle and three-cornered alfalfa hopper. J. Chem. Ecol. 20: 639-650.

Fürstenberg-Hägg, J., M. Zagrobelny, and S. Bak. 2013. Plant defense against insect herbivores. Int. J. Mol. Sci. 14: 10242-10297.

Gómez, S., V. Latzel, Y. M. Verhulst, and J. F. Stuefer. 2007. Costs and benefits of induced resistance in a clonal plant network. Oecologia. 153: 921-930.

Hadley, J. L. 2000. Understory microclimate and photosynthetic response of saplings in an oldgrowth eastern hemlock (Tsuga canadensis L.) forest. Ecoscience. 7: 66-72.

Heil, M., and K. Ploss. 2006. Induced resistance enzymes in wild plants-do 'early birds' escape from pathogen attack?. Naturwissenschaften. 93: 455-460.

Heil, M., and J. Ton. 2008. Long-distance signalling in plant defence. Trends Plant Sci. 13: 264-272.

Heil, M., and D. R. Walters. 2009. Ecological consequences of plant defense signaling, pp. 667-716. In L. C. Van Loon (ed), Advances in Botanical Research Vol. 51, Elsevier, Amsterdam, Netherlands.

Hickin, M., and E. L. Preisser. 2015. Effects of light and water availability on the performance of hemlock woolly adelgid (Hemiptera: Adelgidae). Environ. Entomol. 44: 128-135. 
352 Junglee, S., L. Urban, H. Sallanon, and F. Lopez-Lauri. 2014. Optimized assay for hydrogen

353

354

355

356

357

358

359

360

361

362

363

364

365

366

367

368

369

370

371

372 peroxide determination in plant tissue using potassium iodide. Am. J. Anal. Chem. 5: 730-736.

Kant, M. R., W. Jonckheere, B. Knegt, F. Lemos, J. Liu, C. J. Schimmel, C. A. Villarroel, L. M. S. Ataide, W. Dermauw, J. J. Glas, M. Egas, A. Janssen, T. Van Leeuwen, R. C. Schuurink, M. W. Sabelis, and J. M. Alba. 2015. Mechanisms and ecological consequences of plant defence induction and suppression in herbivore communities. Ann. Bot. 115: 1015-1051.

Maier, C. T., C. R. Lemmon, J. M. Fengler, D. F. Schweitzer, R. C. Reardon. 2011. Caterpillars on the Foliage of Conifers in the Northeastern United States (Revised). USDA FHTET-2011-07:1-153

Mason, C.J., C. Villari, K. Keefover-Ring, S. Jagemann, J. Zhu, P. Bonello, K. F. Raffa. 2017. Spatial and temporal components of induced plant responses in the context of herbivore life history and impact on host. Funct. Ecol. 31: 2034-2050.

Naidoo, R., L. Ferreira, D. K. Berger, A. A. Myburg, and S. Naidoo. 2013. The identification and differential expression of Eucalyptus grandis pathogenesis-related genes in response to salicylic acid and methyl jasmonate. Front. Plant Sci. 4: 43.

Orians, C. 2005. Herbivores, vascular pathways, and systemic induction: Facts and artifacts. J. Chem. Ecol. 31: 2231-2242.

Raffa, K. F., C. J. Mason, P. Bonello, S. Cook, N. Erbilgin, K. Keefover-Ring, J.G. Klutsch, C. Villari, and P. A. Townsend. 2017. Defence syndromes in lodgepole-whitebark pine 
ecosystems relate to degree of historical exposure to mountain pine beetles. Plant Cell Environ. 40: 1791-1806.

Reynolds, G. J., T. R. Gordon, and N. McRoberts. 2019. Using game theory to understand systemic acquired resistance as a bet-hedging option for increasing fitness when disease is uncertain. Plants. 8: 219.

Rigsby, C. M., D. A. Herms, P. Bonello, and D. Cipollini. 2016. Higher defense-associated enzymes may contribute to greater resistance of Manchurian ash to emerald ash borer than a closely related and susceptible congener. J. Chem. Ecol. 42: 782-797.

Rigsby, C. M., C. Villari, D. L. Peterson, D. A. Herms, P. Bonello, and D. Cipollini. 2018. Girdling increases survival and growth of emerald ash borer larvae on Manchurian ash. Agr. For. Entomol. 21: 130-135.

Rigsby, C. M., E. E. Shoemaker, M. M. Mallinger, C. M. Orians, and E. L. Preisser. 2019. Conifer responses to a stylet-feeding invasive herbivore and induction with methyl jasmonate: Impact on the expression of induced defences and a native folivore. Agr. For. Entomol. 21: 227-234.

Rigsby, C. M., M. J. A. Body, A. May, A. Oppong, A. Kostka, N. Houseman, S. Savage, E. R. Whitney, I. G. Kinahan, B. DeBoef, C. M. Orians, H. A. Appel, J. C. Schultz, and E. L. Preisser. In Review. Impact of chronic stylet-feeder infestation on folivore-induced signaling and defenses. Plant Cell Environ.

War, A. R., M. G. Paulraj, T. Ahmad, A. A. Buhroo, B. Hussain, S. Ignacimuthu, and H. C. Sharma. 2012. Mechanisms of plant defense against insect herbivores. Plant Sig. Behav. 7: 1306-1320. 
395 Wasternack, C., and B. Hause. 2013. Jasmonates: biosynthesis, perception, signal transduction 396 and action in plant stress response, growth and development. An update to the 2007 review in Annals of Botany. Ann. Bot. 111: 1021-1058. 
Figures

400 Fig. 1. Positioning of "Local" and "Systemic" stems used in Experiment 2. Local stems directly 401 received either $10 \mathrm{mM}$ MeJA in $0.1 \%$ (v:v) Tween-20 or control solution $(0.1 \%$ Tween-20) and 402 Systemic stems received no treatment.

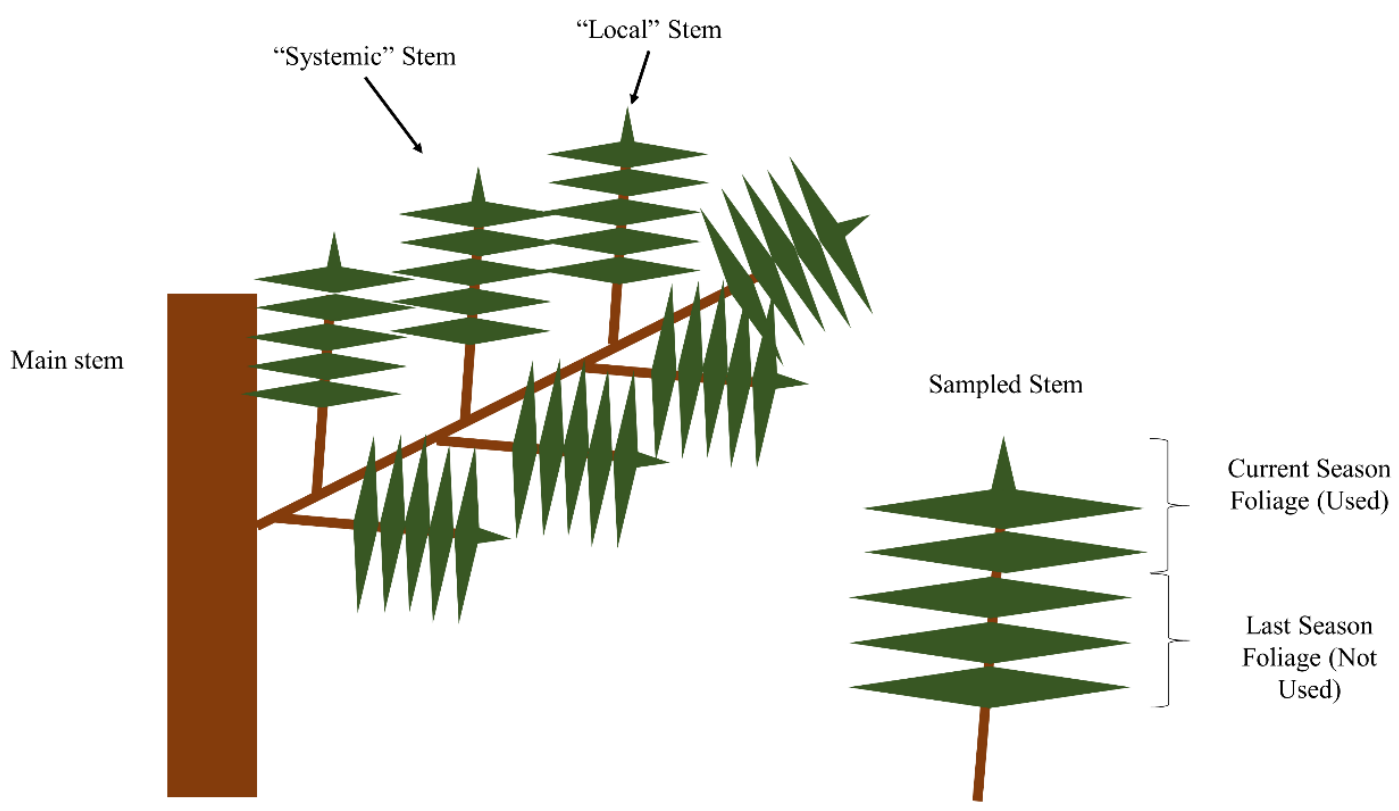


410 Fig. 2. Mean ( \pm SEM) cell wall-bound phenolics (A), lignin (B), and hydrogen peroxide (C)

411 contents of Local (left set of four bars) and Systemic (right set of four bars) foliage infested with

412 hemlock woolly adelgid (+ HWA, hatched right two bars) or not (- HWA, unhatched left two

413 bars) and/or treated with methyl jasmonate (+ MeJA, black bars) or not (- MeJA, white bars).

414 Significant treatment and interaction effects are listed for each response. Different uppercase

415 letters indicate significant differences within foliage position and different lowercase Greek

416 letters indicate significant differences between foliar positions within a treatment combination.

417 For cell wall-bound phenolics $(\mathrm{A}), \operatorname{MeJA}\left(F_{1,36}=1.0 ; P=0.317\right), \mathrm{HWA} \times \mathrm{MeJA}\left(F_{1,36}=0.6 ; P=\right.$ $4180.453)$, stem position $\left(F_{2,36}=1.1 ; P=0.336\right)$, HWA x stem position $\left(F_{2,36}=0.0 ; P=0.971\right)$,

419 MeJA x stem position $\left(F_{2,36}=0.2 ; P=0.836\right)$, and HWA x MeJA x stem position $\left(F_{2,36}=0.3 ; P\right.$ $420=0.726)$ were all not significant predictors. For lignin $(\mathrm{B})$, only MeJA x stem position $\left(F_{2,36}=\right.$ $4210.8 ; P=0.455)$ was not a significant predictor. For hydrogen peroxide $(\mathrm{C}), \operatorname{MeJA}\left(F_{1,36}=2.8 ; P\right.$ $422=0.103)$, HWA $x \operatorname{MeJA}\left(F_{1,36}=1.4 ; P=0.252\right)$, HWA $x$ stem position $\left(F_{2,36}=1.7 ; P=0.193\right)$, 423 MeJA x stem position $\left(F_{2,36}=1.0 ; P=0.377\right)$, and HWA x MeJA x stem position $\left(F_{2,36}=0.2 ; P\right.$ $424=0.805)$ were all not significant predictors.
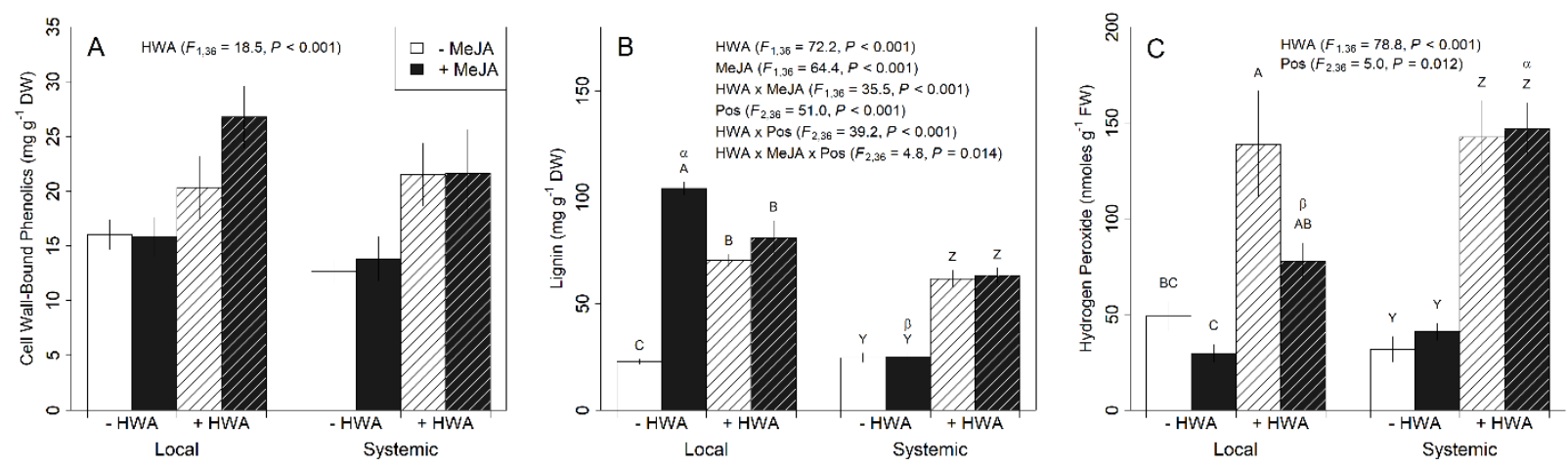
428 Fig. 3. Mean ( \pm SEM) lipoxygenase (A), peroxidase (B), and phenylalanine ammonia lyase $(\mathrm{C})$

429 activities of Local (left set of four bars) and Systemic (right set of four bars) foliage infested with

430 hemlock woolly adelgid (+ HWA, hatched right two bars) or not (- HWA, unhatched left two

431 bars) and/or treated with methyl jasmonate (+ MeJA, black bars) or not (- MeJA, white bars).

432 Significant treatment and interaction effects are listed for each response. Different uppercase

433 letters indicate significant differences within foliage position and different lowercase Greek

434 letters indicate significant differences between foliar positions within a treatment combination.

435 For lipoxygenase activity $(\mathrm{A}), \mathrm{HWA}\left(F_{1,36}=0.9 ; P=0.357\right), \mathrm{HWA} \times \operatorname{MeJA}\left(F_{1,36}=0.4 ; P=\right.$

436 0.526), HWA x stem position $\left(F_{2,36}=1.5 ; P=0.227\right)$, and HWA x MeJA x stem position $\left(F_{2,36}=\right.$

$4370.1 ; P=0.915)$ were all not significant predictors. For peroxidase activity $(\mathrm{B}), \operatorname{MeJA}\left(F_{1,36}=1.2\right.$;

$438 P=0.282)$, HWA $x$ MeJA $\left(F_{1,36}=0.4 ; P=0.535\right)$, stem position $\left(F_{2,36}=0.2 ; P=0.785\right)$, HWA

$439 \mathrm{x}$ stem position $\left(F_{2,36}=1.1 ; P=0.334\right)$, MeJA x stem position $\left(F_{2,36}=0.8 ; P=0.473\right)$, and HWA

$440 \mathrm{x}$ MeJA x stem position $\left(F_{2,36}=1.4 ; P=0.253\right)$ were all not significant predictors. For

441 phenylalanine ammonia lyase activity $(\mathrm{C})$, HWA $\left(F_{1,36}=3.1 ; P=0.088\right)$, MeJA x stem position

$442\left(F_{2,36}=0.0 ; P=0.966\right)$, and HWA x MeJA x stem position $\left(F_{2,36}=1.9 ; P=0.162\right)$ were all not

443 significant predictors.

444
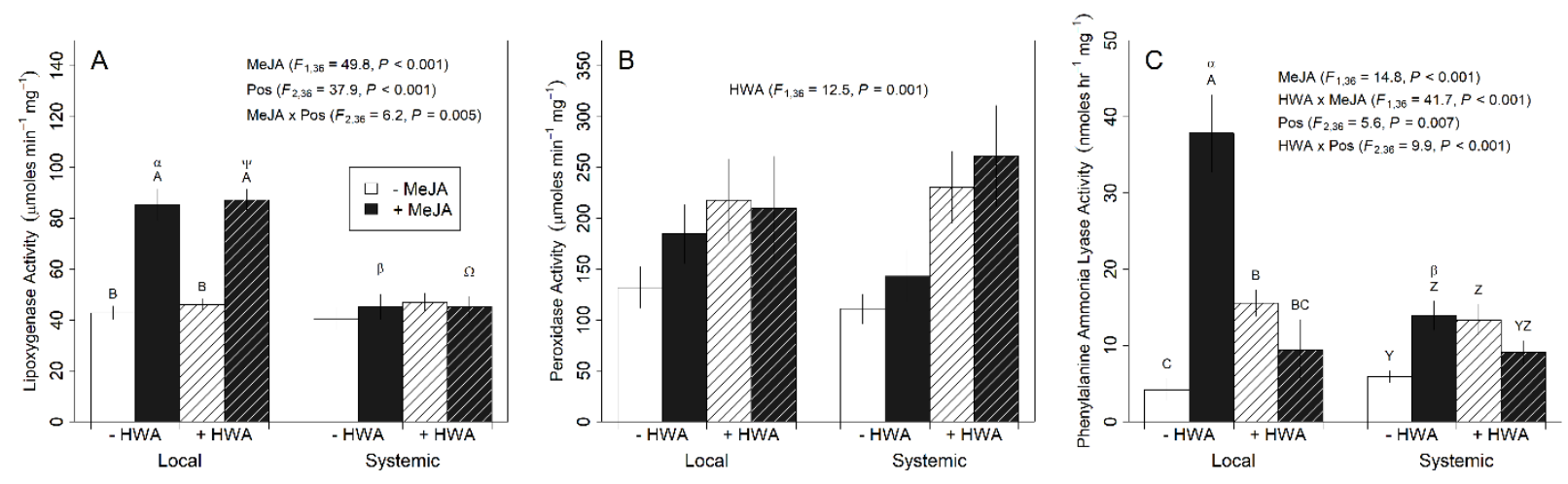